\title{
Reação de genótipos de algodoeiro à mancha-de-alternária
}

\author{
Edivaldo $\mathrm{Cia}^{1,4}$, Milton Geraldo Fuzatto ${ }^{1}$, Wilson Paes de Almeida ${ }^{2}$, Julio Isao Kondo ${ }^{1}$, Margarida Fumiko Ito ${ }^{1}$, Fábio \\ Luiz Ferreira Dias ${ }^{3}$
}

${ }^{1}$ Instituto Agronômico (IAC), Av. Barão de Itapura, 1481, Caixa Postal 28, Campinas - SP, ${ }^{2}$ Instituto Agronômico do Paraná (IAPAR), ${ }^{3}$ Agência Paulista de Tecnologia dos Agronegócios, Departamento de Descentralização e Desenvolvimento, ${ }^{4}$ Bolsista do CNPq.

Autor para correspondência: Edivaldo Cia (cia@iac.sp.gov.br)

Data de chegada: 23/09/2013. Aceito para publicação em: 03/02/2013.

1933

\section{RESUMO}

Cia, E.; Fuzatto, M.G.; Almeida, W.P.; Kondo, J.I; Ito, M.F.; Dias, F.L.F. Reação de genótipos de algodoeiro à mancha-da-alternária. Summa Phytopathologica, v.40, n.1, p.81-83, 2014.

Em três experimentos de campo, realizados em Cambará-PR e Londrina-PR, no ano agrícola 2011/12 e em Piracicaba-SP no ano 2012/13, e sob ocorrência natural do patógeno, foi avaliada a reação de 12 genótipos de algodoeiro à incidência da mancha-de-alternária (Alternaria macrospora). Diferenças altamente significativas entre os genótipos foram observadas nas três localidades, dando margem à formação de três, quatro e seis grupos de reação à doença, conforme o ambiente considerado. Nas posições extremas, e sem que houvesse grandes desvios no desempenho, situaram-se, no grupo dos mais resistentes, os genótipos IAC 08-2031, FMT 709 e BRS 336, e no grupo dos mais suscetíveis FMT 705, IMA CD 08-12427 e DP 555 BG RR. Nos grupos intermediários ocorreram algumas inconsistências, para certos genótipos, o que explica a interação significativa genótipos x locais verificada. Entretanto, como o desempenho menos satisfatório ocorreu na localidade em que a doença incidiu com maior intensidade, tal interação pode traduzir apenas instabilidade fenotípica da resistência ao patógeno, nos genótipos envolvidos.

Palavras-chave adicionais: Gossypium hirsutum L., Alternaria macrospora, resistência genética.

\section{ABSTRACT}

Cia, E.; Fuzatto, M.G.; Almeida, W.P.; Kondo, J.I; Ito, M.F.; Dias, F.L.F. Reaction of cotton genotypes to Alternaria leaf spot. Summa Phytopathologica, v.40, n.1, p.81-83, 2014.

In three field experiments, carried out at Cambará-PR and Londrina-PR in the crop year 2011/12 and at Piracicaba-SP in 2012/13, and under natural incidence of the pathogen, 12 cotton genotypes were evaluated for their reaction to the incidence of Alternaria leaf spot (Alternaria macrospora). Highly significant differences among genotypes were observed at all three localities, allowing the establishment of three, four and six groups of reaction to the disease, according to the considered environment. At the extreme positions, and without great changes in their performance, the group of most resistant genotypes included IAC 08-2031, FMT 709 and BRS 336, and the group of most susceptible genotypes, FMT 705, IMA CD 08-12427 and DP 555 BG RR. Considering the intermediate groups, some inconsistencies were observed for certain genotypes, which explains the significant interaction genotypes $\mathrm{x}$ localities. However, as the less satisfactory performance occurred at the locality where the disease occurred at higher intensity, such interaction may translate only the phenotypic instability of the resistance to the pathogen for the involved genotypes.

Additional keywords: Gossypium hirsutum L., Alternaria macrospora, genetic resistance.

A despeito de relatos sobre sua incidência no algodoeiro existirem desde o final do século 19 e início do século $20(5,11)$, a mancha-dealternária (Alternaria macrospora Zimm) não tem sido considerada doença relevante, pelo menos para cultivares da espécie Gossypium hirsutum L. Danos apreciáveis, porém, de até $20 \%$ na produção, foram a ela atribuídos em cultivares de Gossypium barbadense L. e Gossypium herbaceum L. $(5,7)$.

É possível que para algodoeiros da primeira espécie citada, praticamente a única cultivada no Brasil, essa doença possa tornarse importante, se forem utilizadas, nas lavouras, cultivares muito suscetíveis, Laidou et al. (6). Esse fato pode ser agravado com o emprego de sementes contaminadas, uma vez que esse patógeno pode ser transmitido desse modo, conforme Pizzinatto et al. (9). Daí a importância de se conhecer a reação de cultivares disponíveis no País à doença, de modo que, dentro do possível e do oportuno, sejam utilizadas cultivares resistentes ao citado patógeno, pelo menos em grau médio.

A propósito, alguns trabalhos realizados no Brasil têm demonstrado a existência de diversidade genética entre cultivares e também linhagens, com respeito à resistência a essa doença $(1,2,3,7,8,10)$. $\mathrm{O}$ presente trabalho relata resultados dessa natureza, verificados em cultivares e linhagens disponíveis atualmente no Brasil.

Em três experimentos em condições de campo, dois deles realizados no ano agrícola 2011/12, em Cambará-PR e Londrina-PR, e o terceiro conduzido em Piracicaba-SP, no ano agrícola 2012/13, houve ocorrência natural de Alternaria macrospora, dando margem a que fossem avaliados, com respeito a esse patógeno, os 12 genótipos de algodoeiro constantes da Tabela 1.

Delineados em blocos ao acaso, com cinco repetições, e parcelas 


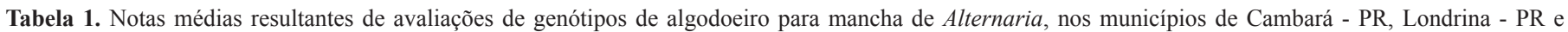
Piracicaba - SP, realizadas em 2011/12 e 2012/13.

\begin{tabular}{lcccc}
\hline GENÓTIPO & CAMBARÁ & LONDRINA & PIRACICABA & MÉDIA \\
\hline IAC 08-2031 & $2,06 \mathrm{~b}^{(1)^{*}}$ & $1,36 \mathrm{a}$ & $1,20 \mathrm{a}$ & 1,54 \\
FMT 709 & $1,80 \mathrm{a}$ & $1,30 \mathrm{a}$ & $1,66 \mathrm{a}$ & 1,59 \\
BRS 336 & $1,74 \mathrm{a}$ & $1,68 \mathrm{~b}$ & $2,00 \mathrm{a}$ & 1,81 \\
FIBERMAX 975 WS & $2,24 \mathrm{~b}$ & $1,84 \mathrm{c}$ & $1,48 \mathrm{a}$ & 1,85 \\
FMT 707 & $1,98 \mathrm{~b}$ & $2,26 \mathrm{~d}$ & $1,62 \mathrm{a}$ & 1,95 \\
NUOPAL RR & $2,20 \mathrm{~b}$ & $1,60 \mathrm{~b}$ & $2,16 \mathrm{~b}$ & 1,99 \\
IMA CD 07-6035 & $2,66 \mathrm{c}$ & $2,14 \mathrm{~d}$ & $1,34 \mathrm{a}$ & 2,05 \\
NUOPAL & $2,26 \mathrm{~b}$ & $1,78 \mathrm{c}$ & $2,48 \mathrm{~b}$ & 2,17 \\
FIBERMAX 951 LL & $2,72 \mathrm{c}$ & $1,78 \mathrm{c}$ & $2,20 \mathrm{~b}$ & 2,23 \\
DP 555 BG RR & $3,06 \mathrm{c}$ & $2,84 \mathrm{e}$ & $2,66 \mathrm{~b}$ & 2,85 \\
IMA CD 08-12427 & $3,40 \mathrm{~d}$ & $3,80 \mathrm{f}$ & $3,08 \mathrm{c}$ & 3,43 \\
FMT 705 & $3,84 \mathrm{~d}$ & $3,54 \mathrm{f}$ & $3,00 \mathrm{c}$ & 3,46 \\
\hline MÉDIA LOCAL & 2,50 & 2,16 & 2,09 & 10,1 \\
C.V. \% & 7,10 & 7,20 & 14,70 & $10,63 * *$ \\
"F" GENÓTIPO & $16,53^{* *}$ & $32,46^{* *}$ & $6,05^{* *}$ & $16,94^{* *}$ \\
"F" LOCAL & & & & $2,91^{* *}$ \\
"F" GENÓTIPO x LOCAL & & & &
\end{tabular}

(1) Teste de Scott \& Knott a $5 \%$.
* Para a análise estatística as notas de 1 a 5 foram transformadas em $\sqrt{\mathrm{x}}$.

constituídas por uma linha de $5 \mathrm{~m}$, contendo 35 plantas, os experimentos foram instalados no mês de novembro, nas três localidades.

Para avaliação, conforme proposto por Cia et al. (3), e com base na proporção de plantas afetadas, no número de folhas com sintomas e na proporção da área foliar com as lesões, foram atribuídas, ao nível de parcelas, notas de 1 a 5 , crescentes com a intensidade dos fatores mencionados, com o seguinte critério: nota 1 - nenhuma planta com sintomas; nota 2 - até $10 \%$ de plantas com uma ou duas folhas mostrando no máximo três lesões; nota 3 - cerca de $30 \%$ de plantas, cada uma com mais de três folhas apresentando em torno de $15 \%$ do limbo ocupado por lesões; nota 4 - de $50 \%$ a $80 \%$ de plantas apresentando a maioria das folhas com cerca de $30 \%$ da superfície tomada por manchas; nota 5 - mais de $80 \%$ das plantas com praticamente todas as folhas mostrando mais de $30 \%$ da área coberta por lesões. Após transformação das notas em $\sqrt{\mathrm{x}}$, os dados foram submetidos à análise da variância e ao teste de agrupamento de médias, de Scott e Knott a $5 \%$ de probabilidade.

Conforme se verifica na Tabela 1 , a análise da variância dos dados revelou efeitos altamente significativos de genótipos, nas três localidades, e também na análise conjunta.

Foi igualmente significativo o efeito de locais, com médias variando de 2,09 a 2,50. A diversidade genética no material estudado fica patente pelo exame do teste de grupamento de médias, que acusou, em Piracicaba, Cambará e Londrina, respectivamente, três, quatro e seis grupos de genótipos, quanto à reação à doença. Sem grandes desvios, nas três localidades, enquadraram-se entre os mais resistentes os genótipos IAC 08-2031, FMT 709 e BRS 336. Igualmente coerentes, nos três ambientes, situaram-se entre os mais suscetíveis FMT 705, IMA CD 08-12427 e DP 555 BG RR.

Nos grupos intermediários pode-se considerar ainda relativamente seguro o desempenho das cultivares FIBERMAX 975 WS, FMT 707 e NUOPAL RR. Nesses grupos, porém, chama atenção a inconsistência de certos genótipos, o que é evidenciado pela interação genótipo $\mathrm{x}$ ambiente significativa. É o caso de FIBERMAX 951 LL e IMA CD
07-6035, cujo desempenho em Cambará destoa do observado nos outros locais. Entretanto, como a reação pior desses genótipos ocorreu na localidade em que a doença incidiu com maior intensidade, tal interação pode estar indicando apenas instabilidade fenotípica da resistência ao patógeno, a exemplo do que foi relatado para outras doenças e genótipos, conforme Fuzatto et al. (4). O que se deve ressaltar é o risco potencial do uso de cultivares com tal desempenho, em ambientes sabidamente propensos a incidências severas dessa doença. Com relação à cultivar NUOPAL, com pior desempenho na localidade em que a doença ocorreu com menor severidade, propõe-se a hipótese de possível existência de variabilidade genética do patógeno, como foi apontado por Mehta et al. (8).

\section{AGRADECIMENTOS}

À FAPESP e ao Instituto Mato-grossense do Algodão pelo apoio na realização deste trabalho.

\section{REFERÊNCIAS BIBLIOGRÁFICAS}

1. Araújo, A. E.; Suassuna, N. D.; Farias, F. J .C.; Freire, E. C. Avaliação da resistência de linhagens de algodoeiro às manchas de Alternaria, Stemphylium e Ramularia. In: Congresso Brasileiro do Algodão, 4., 2003. Goiânia. Anais. EMBRAPA, CNPA, Campina Grande, 2003. 1 CD-ROM.

2. Cia, E.; Fuzatto, M. G.; Chiavegato, E. J.; Gridi-Papp, I. L.; Sabino, J. C. Comportamento de variedades de algodoeiro herbáceo em face a ocorrência da mancha de Alternaria. In: Reunião Nacional do Algodão, 5, Campina Grande, 1988. Resumos dos Trabalhos. Campina Grande, EMBRAPA,CNPA, 1988. p. 26.

3. Cia, E.; Fuzatto, M. G.; Kondo, J. I.; Galbieri, R.; et al. Desempenho de cultivares e linhagens de algodoeiro em face da ocorrência de doenças e nematoides. Resultados de 2007/08 e 2008/09. Boletim Científico Instituto Mato-grossense do Algodão, Cuiabá, . 2011. n. 2. 68p. 
4. Fuzatto, M. G.; Cia, E.; Kondo, J. I. Estabilidade fenotípica, um complemento relevante na avaliação e classificação de genótipos de algodoeiro para resistência a doenças. In: Congresso Brasileiro de Algodão, 8., 2011. São Paulo. Campina Grande, Anais, EMBRAPA,CNPA, 2011. 1 CD-ROM.

5. Hillocks, R. J. Fungal disease of the leaf. In: R. J. Hillocks. Cotton diseases. Ed.. C.A.B. Wallingford, Internacional. 1992. p. 191-238.

6. Laidou, I. A.; Koulakiotu, E. K.; Thanassoulopoulus, C. C. First reporter of stem canker caused by Alternaria alternate on cotton. Plant Disease v.84, n.1: p. 103, 2000.

7. Lima, E. F.; Carvalho, J. M. F. C.; Batista, F. A. S.; Santos, J. W. Avaliação do nível de resistência de linhagens e cultivares de algodoeiro à mancha foliar causada por Alternaria sp. EMBRAPA, CNPA, Campina Grande.
Comunicado Técnico n.40, 1995. 4 p.

8. Mehta, Y. R.; Teixeira, E. A.; Cunha, H.; Erivaldo, J.; Ruano, O. Resposta diferencial das cultivares de algodoeiro a Alternaria macrospora. Summa Phytopathologica, Botucatu, v.32,n.2: p. 186-187, 2006.

9. Pizzinatto, M. A.; Cia, E.; Parisi, J. J. D.; Medina, P. F.; Fuzatto, M. G. Associação de Alternaria macrospora e A. alternata em sementes do algodoeiro e sua ação patogênica. Summa Phytopathologica, Botucatu, v.31, n.4 p. 311-318, 2005.

10. Suassuna, N. D,; Morello, C. L.; Freire, E. C.; Araújo, A. E.; Santos, J. W.; Andrade, F. P.; Fernandez Júnior, I.; Assunção, J. H.; Bezerra W. Resistência de cultivares de algodoeiro às manchas de Ramularia, Alternaria, mancha-angular e "doença azul" no Estado de Goiás. In: Congresso Brasileiro de Algodão, 4, 2003, Goiânia. Campina Grande, EMBRAPA, CNPA. 2003. 1 CD- ROM 